\title{
A organização do conteúdo em periódicos científicos: uma análise da Arquitetura da Informação
}

\author{
Paula Caroline Schifino Jardim Passos \\ Doutora; Universidade Federal do Rio Grande do Sul, Porto Alegre, RS, Brasil; \\ paulacarolinejardim@gmail.com \\ Sônia Elisa Caregnato \\ Doutora; Universidade Federal do Rio Grande do Sul, Porto Alegre, RS, Brasil; \\ sonia.caregnato@ufrgs.br
}

\begin{abstract}
Resumo: A organização é um componente da Arquitetura da Informação que trata da classificação do conteúdo de um sistema. Em revistas científicas eletrônicas, a organização impacta a interação do usuário com o conteúdo e a visibilidade dos artigos publicados. Assim, o objetivo deste artigo é verificar como funcionam os sistemas de organização das revistas científicas eletrônicas. Para análise, foram selecionadas três revistas de relevância para ciência e com elevados fatores de impacto na área multidisciplinar, que são as seguintes: Nature, Science e PLOS Biology. O método escolhido foi a inspeção por lista de verificação, realizada a partir de sentenças teste, descritas com base em autores de referência na área. A análise considerou se, quando empregados nas revistas, os esquemas de organização dividem a informação em seções bem definidas e exclusivas e se suportam um processo de aprendizagem associativa que possibilita ao usuário fazer novas conexões. Verificou-se, também, se as estruturas empregadas nas revistas organizam o conteúdo em agrupamentos lógicos e beneficiam a pesquisa, a navegação, a filtragem e a vinculação da informação. Além dos tradicionais esquemas e estruturas de organização, o estudo verifica se as revistas apresentam maneiras alternativas de classificar informações digitais baseadas na organização colaborativa do conteúdo e geradas a partir de marcações dos usuários (tags). Como resultados, a pesquisa apresenta os mapeamentos dos sistemas de organização das revistas analisadas. A análise ainda valida indicadores que podem ser aplicados para a avaliação e para o aprimoramento dos sistemas de organização de revistas científicas.
\end{abstract}

Palavras-chave: Periódico científico. Arquitetura da Informação. Colaboração.

\section{Introdução}

A organização é o componente da Arquitetura da Informação que se refere à classificação e à categorização de conteúdo de um sistema. Em ambientes digitais com uma grande quantidade de conteúdo, como é o caso das revistas 
científicas eletrônicas, o sistema de organização pode influenciar na qualidade da interação e interferir nos resultados de busca. Dessa forma, influencia diretamente os objetivos dos leitores e autores de revistas científicas.

Este artigo apresenta os resultados da avaliação das revistas Nature, Science e PLOS Biology em relação aos seus sistemas de organização. O objetivo é observar como as revistas organizam conteúdo e como a interação e o trabalho colaborativo entre os usuários podem ser beneficiados quando as revistas consideram aspectos relacionados a essa parte da Arquitetura da Informação.

As primeiras metodologias de avaliação de revistas científicas datam do final do século XX (BRAGA; OBERHOFER, 1982; KRZYZANOWSKI; KRIEGER; DUARTE，1991; CHRESSANTHIS，A.; CHRESSANTHIS，D., 1993). Os critérios inicialmente concebidos para avaliação eram voltados para as revistas impressas. Com a transposição das revistas científicas para o formato eletrônico, as metodologias de avaliação passaram a incluir também aspectos relacionados a esse meio (SARMENTO e SOUZA, 2002; FACHIN, 2002; FRANCKE, 2009; MUKHERJEE, 2010; ZUDILOVA-SEINSTRA et al., 2014).

Passos e outros (2018) apontam, entretanto, a necessidade de metodologias de avaliação que contemplem mais amplamente os aspectos das revistas científicas relacionados ao contexto digital, como a Arquitetura da Informação e em seus sistemas. Essa preocupação se torna ainda mais relevante quando são consideradas as constantes inovações tecnológicas e atualizações nos sistemas informatizados.

Nesse sentido, a presente pesquisa apresenta metodologia para avaliação do sistema de organização das revistas científicas eletrônicas. Esse método estabelece sentenças teste que orientam a inspeção detalhada da estrutura organizacional do periódico. Os critérios postulados visam aprimorar as etapas construtivas do sistema, de modo que se perceba sua qualidade na apresentação final, ou seja, na interface.

A metodologia ainda inclui indicadores referentes ao trabalho colaborativo em rede. O tema da colaboração tem sido contemplado em recentes publicações de autores de referência no tema projeto de interface (WODTKE; 
GOVELLA， 2009; GARRETT, 2011; RUSSELL-ROSE; TATE, 2013; ROSENFELD; MORVILLE; ARANGO, 2015; PREECE; ROGERS; SHARP, 2015). Assim, cabe o estudo da Arquitetura da Informação de revistas científicas eletrônicas também sob o viés da colaboração.

Nos próximos itens, tem-se uma breve revisão bibliográfica a respeito dos esquemas e estruturas de organização, que serve como base para a apresentação da pesquisa. Em seguida, apresenta-se a metodologia aplicada e a análise dos resultados da pesquisa.

\section{0 sistema de organização}

O sistema de organização é definido didaticamente, entre os componentes da Arquitetura da Informação, para tratar da classificação e da categorização do conteúdo. Rosenfeld, Morville e Arango (2015) o subdividem em esquemas e estruturas. Os esquemas de organização delimitam as ligações entre os elementos, classificando-se em exatos e ambíguos. Kalbach (2009) utiliza nomes diferentes para os esquemas, mas com o mesmo significado. Ele os denomina de objetivos e subjetivos. Há também, uma outra classificação, os esquemas híbridos que, como sugere o próprio nome, mesclam os demais esquemas.

Os esquemas exatos são aqueles que organizam a informação por ordenamentos bem definidos e exclusivos. Esses esquemas são adequados para buscas onde a informação é conhecida, pois exigem que o usuário saiba o nome correto do recurso que está procurando. Nesse caso, nenhuma subjetividade está envolvida. Rosenfeld, Morville e Arango (2015) e Kalbach (2009) destacam os esquemas de organização alfabético, cronológico e geográfico.

O esquema exato alfabético é a principal forma de organização de dicionários, livrarias, bibliotecas e enciclopédias. Kalbach (2009) considera esse sistema pouco eficiente, pois não informa o relacionamento entre os objetos de maneira significativa. Já o esquema exato cronológico agrega alguma informação, pois notifica sobre a data do arquivo. 
O último esquema de organização exato é o geográfico. Para Rosenfeld, Morville e Arango (2015), questões econômicas, políticas e sociais são, na maioria das vezes, vinculadas à localização. Outro detalhe que evidencia o esquema geográfico é a popularização dos dispositivos móveis de localização. Mapas e sistemas de geolocalização são maneiras pelas quais muitas pessoas interagem com esquemas geográficos de organização.

Os esquemas ambíguos são os principais modos de estruturar a navegação em um site. Os esquemas de organização ambíguos mais comuns e notáveis são os seguintes: esquema de organização por tópico, esquema orientado à tarefa, esquema orientado ao público e esquema orientado à metáfora. Conforme Rosenfeld, Morville e Arango (2015), esses esquemas apresentam a informação sem uma definição exata, já que estão ligados à subjetividade humana da linguagem.

A subjetividade pode tornar os esquemas ambíguos mais difíceis de usar do que os exatos. Mesmo assim, na grande maioria das vezes, sua aplicação se faz mais adequada e mais vantajosa. As razões para isso são muito simples, usuários nem sempre sabem o que estão procurando, por vezes não sabem o rótulo correto, ou possuem poucos fragmentos de informação e, por conseguinte, não conseguem expressar-se corretamente. Assim, os esquemas exatos nem sempre são uma opção válida para os usuários.

O esquema ambíguo de organização por tópico, assunto ou tema é muito comum e bastante utilizado em sites. Conforme Kalbach (2009), usuários que não sabem exatamente o que procuram gostam de navegar por tópicos. Esses esquemas de organização podem aparecer no formato de diretórios, estruturas em árvore e menus.

O esquema orientado à tarefa é um meio eficaz para organizar a informação em aplicativos online e em sites com muitos recursos interativos. Esse modelo permite a organização do conteúdo em uma coleção de processos, funções e tarefas, que são adequados quando a ação do usuário é a prioridade. Rosenfeld, Morville e Arango (2015) observam que poucos sites são organizados exclusivamente por tarefa. Na maioria das vezes, para proporcionar 
uma melhor utilização do sistema, este modelo de organização está integrado em modelos híbridos, por exemplo, tarefa e tópico.

Segundo Rosenfeld, Morville e Arango (2015), quando o objetivo é falar a diferentes grupos de usuários, o modelo indicado é o orientado ao público ou por grupo de audiência. Estruturalmente, este modelo divide o conteúdo de um site e o organiza de forma que desperte o interesse para públicos específicos. Modelos de organização orientados a grupos de audiência podem ser abertos ou fechados. Esquemas abertos possibilitam que usuários de uma determinada audiência acessem o conteúdo organizado para outros públicos. Já os esquemas fechados impedem a livre movimentação de usuários entre as áreas específicas do site.

$\mathrm{O}$ propósito do esquema orientado à metáfora é possibilitar que o usuário compreenda e experimente conceitos novos com base em experiências anteriores. Assim, por justaposição dos atributos semelhantes, o novo conceito é reconhecido e compreendido. Rosenfeld, Morville e Arango (2015) explicam que as metáforas em uma interface, além de ajudarem na compreensão do conteúdo e na navegação intuitiva, também geram novas ideias sobre a organização e o funcionamento de um site.

Finalizando os esquemas, há ainda os regimes híbridos ou mistos, que consistem na junção de esquemas exatos e ambíguos. Rosenfeld, Morville e Arango (2015) advertem que é preciso observar que os esquemas devem ser combinados sempre em prol da organização e da consistência da informação. A interface pode parecer confusa para o usuário quando são combinados vários esquemas. Portanto, essa medida deve ser tomada apenas quando realmente se faz necessário.

Já as estruturas, referem-se a como o conteúdo está distribuído. As estruturas de organização exercem um papel muito importante no planejamento de um ambiente de informação, pois elas definem os modos pelos quais os usuários poderão navegar. Rosenfeld, Morville e Arango (2015) classificam as estruturas em hierárquicas, bases de dados relacional e hipertextos. Garrett (2011) acredita que são possíveis muitas formas de estrutura, mas ele as generaliza em quatro classes: sequencial, hierárquica, matricial ou orgânica. 
A estrutura hierárquica, conforme Rosenfeld, Morville e Arango (2015), parte de uma tela inicial com conteúdo geral, para outras telas de conteúdo específico. Na maioria das vezes, em uma hierarquia muito estreita e profunda os usuários necessitam de um número excessivo de cliques para encontrarem aquilo que procuram. Por outro lado, em uma hierarquia rasa e larga os usuários encontram muitas opções no menu principal.

Rosenfeld, Morville e Arango (2015) destacam que, assim como nos sistemas ambíguos, o grande desafio de organizar por hierarquia é criar categorias exclusivas. Quando isso não acontece, a hierarquia perde o seu valor. Garrett (2011) explica que essa estrutura é a mais utilizada porque o conceito de relacionamento hierárquico proporciona fácil compreensão do usuário e porque essa é a forma comum de trabalho dos computadores. Ele também a chama de estrutura em árvore ou em leque.

A estrutura por base de dados relacionais armazena conceitos e valores específicos, ligados aos documentos, em um conjunto de relações ou tabelas. Conforme Rosenfeld, Morville e Arango (2015), esse modo de organização implica a utilização e o conhecimento de metadados e de banco de dados. Eles afirmam que, mesmo em pequenos sistemas, definir e mapear as relações formais entre elementos de metadados e vocabulário controlado é tarefa extremamente árdua, mesmo para os arquitetos de informação.

Para Rosenfeld, Morville e Arango (2015), o sucesso da implementação da estrutura por base de dados relacional requer a perspicácia de um programador profissional, especialista em banco de dados. Em grandes sistemas, a recomendação é que se utilizem softwares específicos para gerenciamento de conteúdo, a fim de administrar metadados e vocabulários controlados.

A informação também pode ser organizada por hipertextos. Rosenfeld, Morville e Arango (2015) explicam que essa é uma estruturação em rede, composta de forma não linear. Garrett (2011) a chama de matricial, ou em mapa, e explica que essa estrutura permite que o usuário se mova de um nó ao outro em duas ou mais dimensões. Ele comenta que a estrutura matricial é normalmente utilizada para permitir que usuários com diferentes interesses 
naveguem pelo mesmo conteúdo, porque cada interesse pode ser associado a um eixo da matriz. Por exemplo, se alguns usuários preferem procurar um determinado produto pela cor, enquanto outros preferem buscar pelo tamanho, a matriz pode atender a ambos os grupos.

Garrett (2011) também destaca a estrutura orgânica, ou rizomática, que é construída sem base em qualquer padrão. Nela, os nós são conectados caso a caso e a arquitetura não tem um conceito de sessões. Essa organização é adequada à exploração de tópicos cuja relação não é clara ou está em evolução. $\mathrm{O}$ autor considera essa estrutura própria para casos em que se deseja encorajar o sentimento de livre exploração, em sites educacionais ou de entretenimento, por exemplo. Entretanto, isso pode representar uma dificuldade se o usuário necessitar encontrar o caminho de volta para alguma parte do conteúdo, porque a estrutura não provê a ele o senso de localização na arquitetura.

Segundo Garrett (2011), a estrutura ainda pode ser sequencial, ou linear, o tipo mais básico de arquitetura da informação. Essa estrutura é de simples manuseio para o usuário, pois se trata de um tipo de experiência presente em outros meios, como livros, áudio e vídeo. Para web, o tipo sequencial é mais comumente usado em estruturas pequenas, como em setores de compras online. Em maior escala, essa estrutura tende a limitar-se a aplicações instrucionais, onde a ordem de apresentação dos conteúdos é importante para atender às necessidades de aprendizagem do usuário.

Por fim, o conteúdo pode ser organizado também por classificação colaborativa, ou livre marcação. A classificação colaborativa consiste em marcar objetos com tags - etiquetas, rótulos, marcações - definidas por outros usuários. De acordo com Kalbach (2009), o conjunto de tags é chamado de classificação social ou folksonomy.

Rosenfeld, Morville e Arango (2015) explicam que essas tags servem como marcos para a navegação social, realizada por recomendação de conteúdo. Conforme os autores, do ponto de vista técnico, a marcação colaborativa nada mais é que a incorporação de metadados do usuário para o benefício pessoal visando a posterior recuperação - ou social, em prol do coletivo. 


\section{Metodologia}

Neste artigo, importa verificar como funcionam os atuais sistemas de organização das revistas científicas eletrônicas. O método escolhido foi a inspeção por lista de verificação, realizada a partir de sentenças teste, descritas com base nos autores de referência na área Rosenfeld, Morville e Arango (2015), Garrett (2011), Kalbach (2009) e Francke (2008). Foram selecionadas três revistas de relevância para a ciência e com elevados fatores de impacto na área multidisciplinar, que são as seguintes: Nature, Science e PLOS Biology. O quadro 1 apresenta as sentenças descritas para a inspeção e os autores utilizados como referência para composição dessas sentenças.

Quadro 1 - Metodologia de análise do sistema de organização

\begin{tabular}{|c|c|c|}
\hline Variável & Condição & Fonte \\
\hline \multicolumn{3}{|c|}{ Organização } \\
\hline \multicolumn{3}{|l|}{1 Esquemas } \\
\hline $\begin{array}{l}\text { 1.1 Esquema } \\
\text { exato }\end{array}$ & $\begin{array}{l}\text { - Quando empregados na revista, os esquemas exatos } \\
\text { dividem a informação em seções bem definidas e } \\
\text { exclusivas? }\end{array}$ & $\begin{array}{c}\text { Rosenfeld, } \\
\text { Morville e } \\
\text { Arango (2015), } \\
\text { Francke (2008) }\end{array}$ \\
\hline $\begin{array}{l}\text { 1.2 Esquema } \\
\text { ambíguo } \\
\text { (arbitrário) }\end{array}$ & $\begin{array}{l}\text { - Quando empregados na revista, os esquemas ambíguos } \\
\text { suportam um processo de aprendizagem associativa que } \\
\text { possibilita ao usuário fazer novas conexões? }\end{array}$ & $\begin{array}{c}\text { Rosenfeld, } \\
\text { Morville e } \\
\text { Arango (2015), } \\
\text { Francke (2008) }\end{array}$ \\
\hline \multicolumn{3}{|l|}{2 Estruturas } \\
\hline $\begin{array}{l}2.1 \\
\text { Hierárquica } \\
\text { (top-down) }\end{array}$ & $\begin{array}{l}\text { - Quando empregadas nas revistas, as estruturas } \\
\text { hierárquicas, além de serem facilmente compreendidas, } \\
\text { organizam o conteúdo em agrupamentos lógicos, } \\
\text { partindo de assuntos gerais para assuntos específicos? }\end{array}$ & $\begin{array}{l}\text { Rosenfeld, } \\
\text { Morville e } \\
\text { Arango (2015), } \\
\text { Francke (2008), } \\
\text { Garrett (2011) }\end{array}$ \\
\hline $\begin{array}{l}2.2 \text { Base de } \\
\text { dados } \\
\text { relacional } \\
\text { (bottom-up) }\end{array}$ & $\begin{array}{l}\text { - Quando empregadas na revista, as estruturas de dados } \\
\text { relacionados possibilitam a fácil pesquisa, navegação, } \\
\text { filtragem e vinculação da informação, partindo de } \\
\text { assuntos específicos para os gerais? }\end{array}$ & $\begin{array}{l}\text { Rosenfeld, } \\
\text { Morville e } \\
\text { Arango (2015), } \\
\text { Francke (2008), } \\
\text { Garrett (2011) }\end{array}$ \\
\hline 2.3 Hipertexto & $\begin{array}{c}\text { - Quando empregadas nas revistas, as estruturas de } \\
\text { hipertexto possibilitam uma navegação orgânica a partir } \\
\text { de componentes interligados por links? }\end{array}$ & $\begin{array}{l}\text { Rosenfeld, } \\
\text { Morville e } \\
\text { Arango (2015), } \\
\text { Francke (2008), } \\
\text { Garrett (2011) }\end{array}$ \\
\hline $\begin{array}{l}3 \\
\text { Classificação } \\
\text { social }\end{array}$ & $\begin{array}{l}\text { - O sistema oferece, diferentemente dos vocabulários } \\
\text { controlados (rígidos e impessoais), maneiras alternativas } \\
\text { de classificar informações digitais baseadas na } \\
\text { organização colaborativa do conteúdo e gerada a partir } \\
\text { de marcações (tags) feitas pelos usuários? }\end{array}$ & $\begin{array}{l}\text { Rosenfeld, } \\
\text { Morville e } \\
\text { Arango (2015); } \\
\text { Kalbach (2009) }\end{array}$ \\
\hline
\end{tabular}

Fonte: Elaborado pelas autoras. 


\section{Análise das revistas Nature, Science e PLOS Biology}

Este item apresenta a análise do sistema de organização das revistas Nature, Science e PLOS Biology e a discussão dos resultados obtidos. As sentenças teste citadas na metodologia orientam a revisão dos esquemas exatos e ambíguos, das estruturas e da classificação colaborativa nessas revistas.

\subsection{Esquemas exatos e ambíguos}

Em relação aos esquemas de organização, a análise das revistas Nature, Science e PLOS Biology verificou se, quando empregados na revista, os esquemas exatos dividem a informação em seções bem definidas e exclusivas; e se os esquemas ambíguos suportam um processo de aprendizagem associativa que possibilita ao usuário fazer novas conexões.

A análise permitiu verificar que os artigos são organizados nas revistas Nature, Science e PLOS Biology por sua data de publicação, ou seja, utilizando o esquema exato cronológico. Este esquema de organização é adequado para as revistas científicas, pois ressalta um aspecto importante dos artigos, sua data de liberação. A Figura 1 mostra o esquema exato cronológico devidamente aplicado na revista Nature.

Figura 1 - Esquema exato cronológico na revista Nature

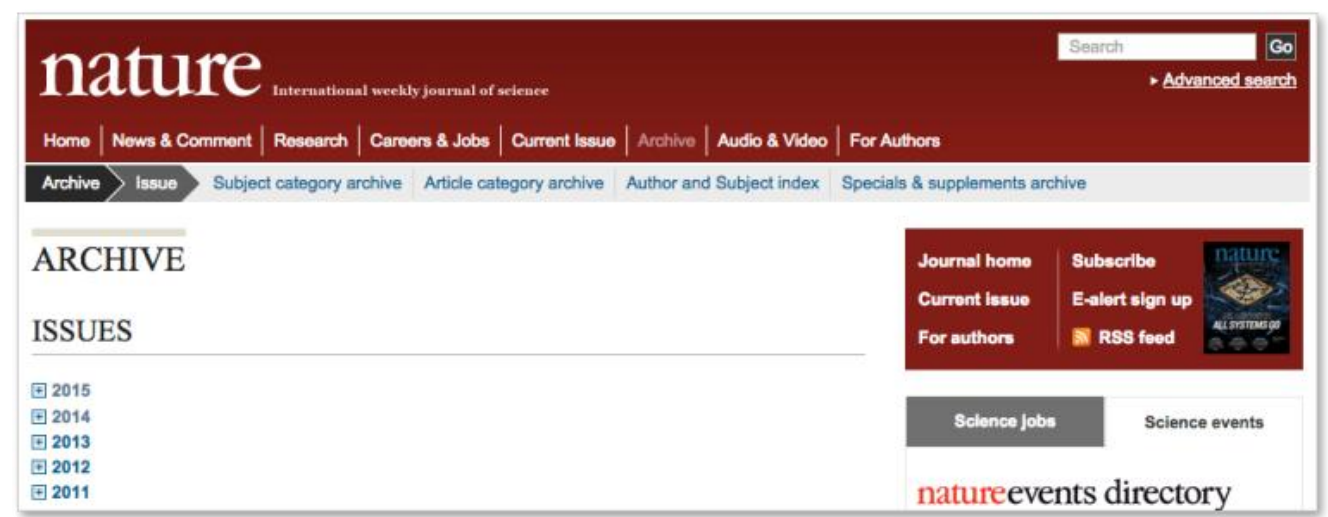

Fonte: Nature (2015). 
A Figura 2 mostra o esquema exato cronológico na revista PLOS Biology. Essa revista organiza as edições em ordem cronológica utilizando rótulos iconográficos para cada mês do ano. O recurso visual aplicado torna o esquema de organização mais informativo e atrativo.

Figura 2 - Esquema exato cronológico na revista PLOS Biology

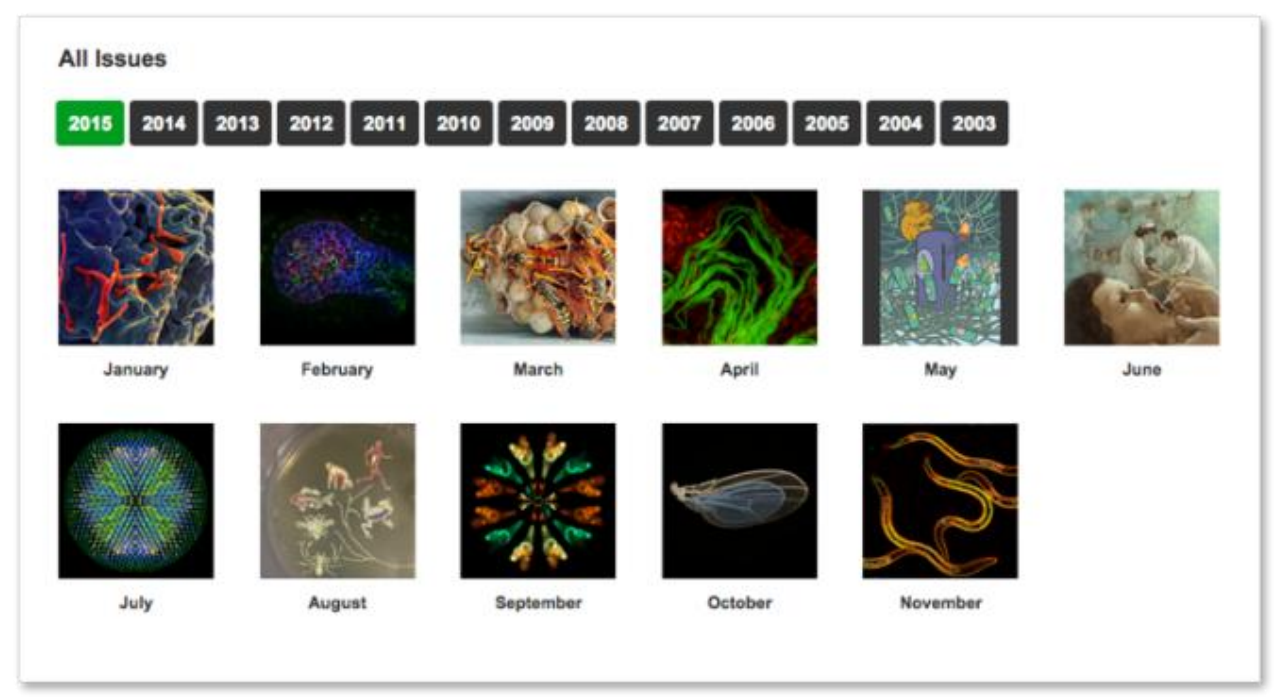

Fonte: Elaborado pelas autoras com imagens da revista PLOS Biology (2015).

A análise não identificou a utilização do esquema de organização alfabético nas revistas Nature, Science e PLOS Biology. Realmente, o esquema alfabético não seria indicado para organização do conteúdo das revistas. Devido ao grande número de itens, a classificação alfabética seria inadequada e impraticável. Esse esquema também não agrega informações que contribuam para a organização dos artigos.

Certos tipos de informação se encaixam melhor a determinados tipos de classificação. Segundo Rosenfeld, Morville e Arango (2015), o esquema exato alfabético é utilizado com frequência em combinação com outros esquemas, para organizar informações como sobrenome, produto, serviço, departamento, formato, entre outras. O esquema exato geográfico também não foi identificado em nenhuma das três revistas analisadas. 
Quanto aos esquemas ambíguos, verificou-se sua ampla utilização nas revistas Nature, Science e PLOS Biology. Os esquemas ambíguos não são organizados de uma maneira ordenada como os esquemas exatos, mesmo assim, consistem nos principais modos de estruturar a navegação nos sites da internet em geral. Isso acontece porque essa forma de estruturação os torna adequados ao perfil do navegador, que busca informação, mas nem sempre conhece o rótulo correto ou sabe exatamente o que procura.

Rosenfeld, Morville e Arango (2015) argumentam que a busca por informação é um processo iterativo, ou seja, é repetido várias vezes até que se chegue ao resultado. Assim, aquilo que se encontra no início de uma busca poderá influenciar e determinar aquilo que se irá procurar e encontrar posteriormente. Para os autores, isso envolve uma aprendizagem associativa, quando o usuário pode aprender ao longo do caminho. Por agruparem pontos de modo intelectualmente significativos, os esquemas ambíguos suportam muito bem o modo iterativo de busca por informações, possibilitando que o usuário faça novas conexões e chegue a melhores conclusões.

A organização por tópico é um esquema ambíguo muito comum e extremamente utilizado em sites. Os tópicos podem aparecer no formato de diretórios, estruturas em árvore e menus. Os sumários das três revistas analisadas estão organizados por tópicos, como exemplifica a Figura 3. Esses agrupamentos refletem a estrutura de cada revista.

Figura 3 - Organização ambígua por tópico na revista Nature

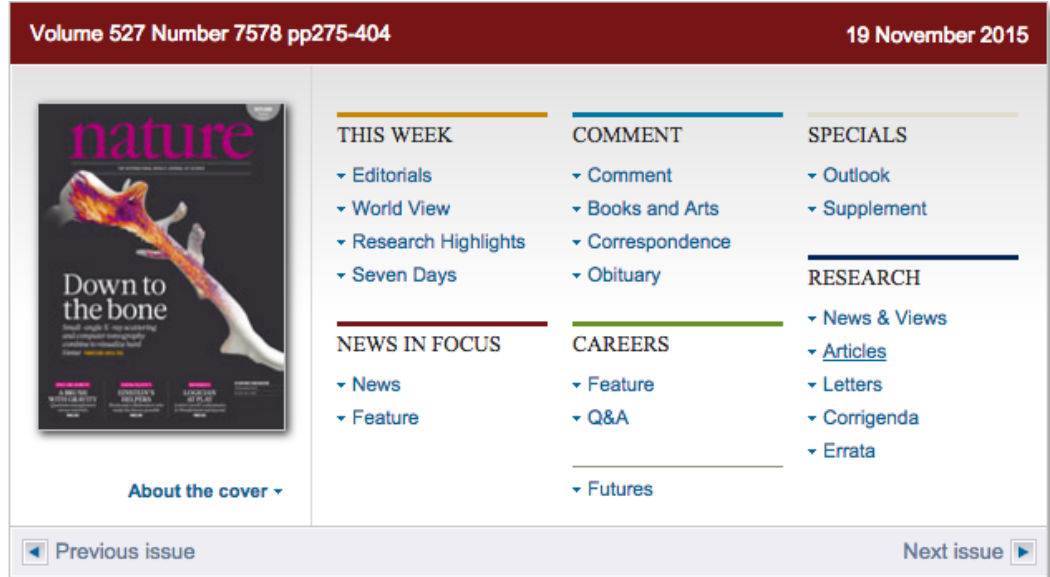

Fonte: Nature (2015). 
A revista PLOS Biology também utiliza a organização por tópicos para encaminhar às partes constituintes dos artigos, como mostra o destaque da Figura 4. Em um menu lateral, as opções de navegação local mostram o conteúdo da revista de maneira bastante eficiente, utilizando o esquema ambíguo por tópico.

Figura 4 - Organização ambígua por tópicos na revista PLOS Biology

\section{APOE Stabilization by Exercise Prevents Aging Neurovascular Dysfunction and Complement Induction}

Ileana Soto, Leah C. Graham, Hannah J. Richter, Stephen N. Simeone, Jake E. Radell, Weronika Grabowska,

W. Keith Funkhouser, Megan C. Howell, Gareth R. Howell 回

Published: October 29, 2015 • DOI: 10.1371/journal.pbio.1002279

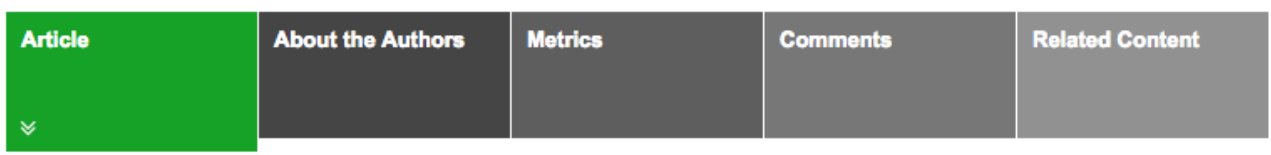

\begin{tabular}{l} 
Abstract \\
Author Summary \\
Introduction \\
Results \\
Discussion \\
Materials and Methods \\
Supporting Information \\
Acknowledgments \\
Author Contributions \\
References \\
\hline Reader Comments (0) \\
Media Coverage (6) \\
Figures
\end{tabular}

Figures

\begin{abstract}
Aging is the major risk factor for neurodegenerative diseases such as Alzheimer's disease, but little is known about the processes that lead to age-related decline of brain structures and function. Here we use RNA-seq in combination with high resolution histological analyses to show that aging leads to a significant deterioration of neurovascular structures including basement membrane reduction, pericyte loss, and astrocyte dysfunction. Neurovascular decline was sufficient to cause vascular leakage and correlated strongly with an increase in neuroinflammation including up-regulation of complement component C1QA in microglia/monocytes. Importantly, long-term aerobic exercise from midlife to old age prevented this age-related neurovascular decline, reduced $\mathrm{C} 1 \mathrm{QA}+$ microglia/monocytes, and increased synaptic plasticity and overall behavioral capabilities of aged mice. Concomitant with agerelated neurovascular decline and complement activation, astrocytic Apoe dramatically decreased in aged mice, a decrease that was prevented by exercise. Given the role of APOE in maintaining the neurovascular unit and as an anti-inflammatory molecule, this suggests a possible link between astrocytic Apoe, age-related neurovascular dysfunction and microglia/monocyte activation. To test this, Apoe-deficient mice were exercised from midlife to old age and in contrast to wild-type (Apoe-sufficient) mice, exercise had little to no effect on age-related neurovascular decline or microglia/monocyte activation in the absence of APOE.
\end{abstract}

Fonte: PLOS Biology (2015).

A revista PLOS Biology também utiliza a organização ambígua por tópicos para estruturar coleções de artigos agrupados por temas específicos, como apresenta a Figura 5. 
Figura 5 - Organização de coleções na revista PLOS Biology

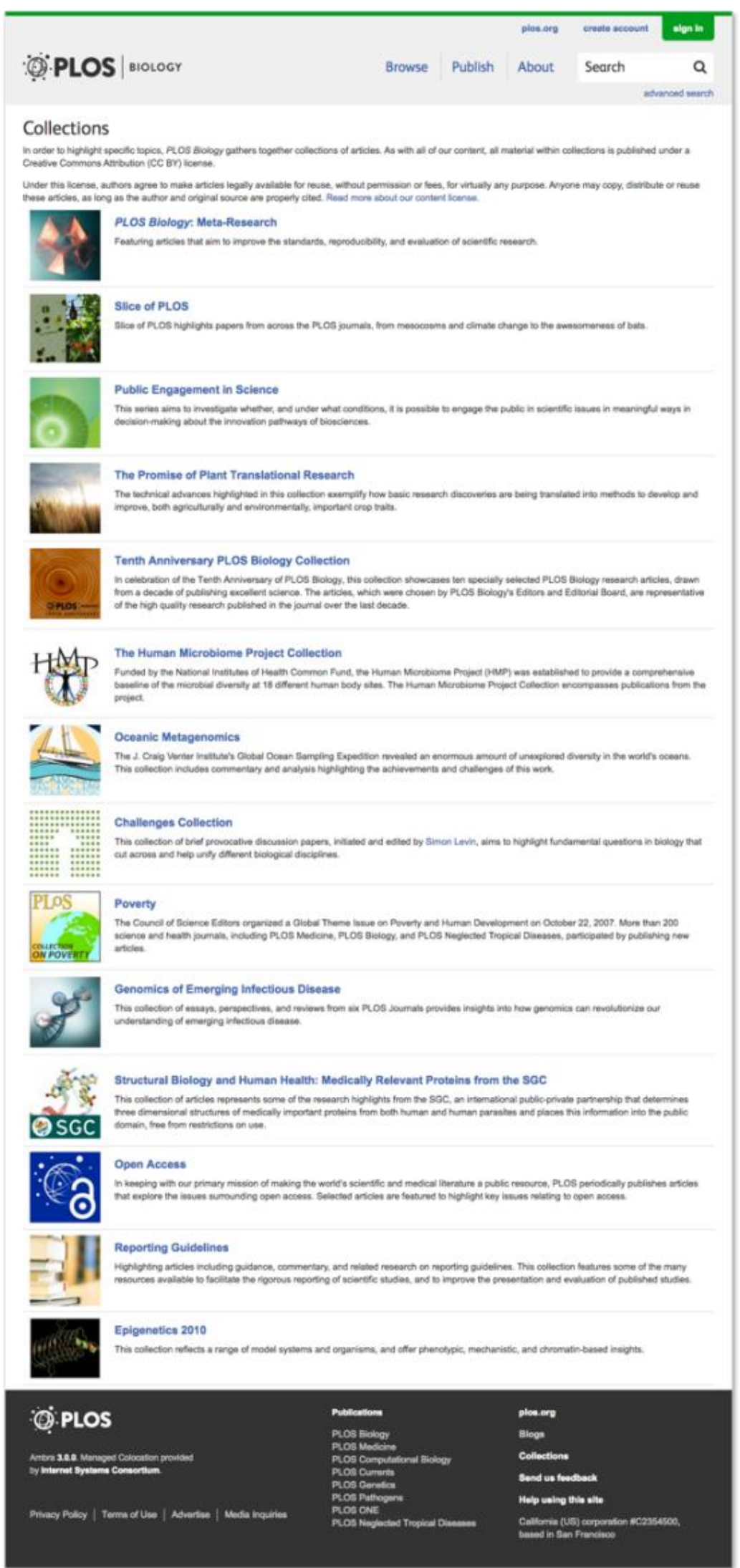

Fonte: PLOS Biology (2015). 
Tópicos são agrupamentos convencionados ou construções culturais que podem mudar ao longo do tempo. No projeto de um esquema de organização por tópico, é necessário delimitar a sua dimensão de abrangência. Por exemplo, uma grande enciclopédia online possui uma grande amplitude. No contexto das revistas científicas, os tópicos cobrem campos específicos de estudo, são limitados em largura e estão diretamente relacionados à temática de pesquisa, por exemplo, cobrem apenas tópicos relacionados a Arquitetura de Informação. Um esquema ambíguo por tópico retrata o universo do conteúdo de uma dada área do sistema.

As revistas Nature e PLOS Biology também aplicam o esquema de organização orientado à tarefa. Como visto, esse esquema permite a organização do conteúdo em um grupo de processos, funções e tarefas, adequados quando a interação com o usuário é a prioridade. A revista Nature organiza as funções disponíveis no site em caixas separadas e áreas específicas. No exemplo da Figura 6, tem-se a organização ambígua por tarefa dos links para redes sociais.

Figura 6 - Organização ambígua por tarefa na revista Nature

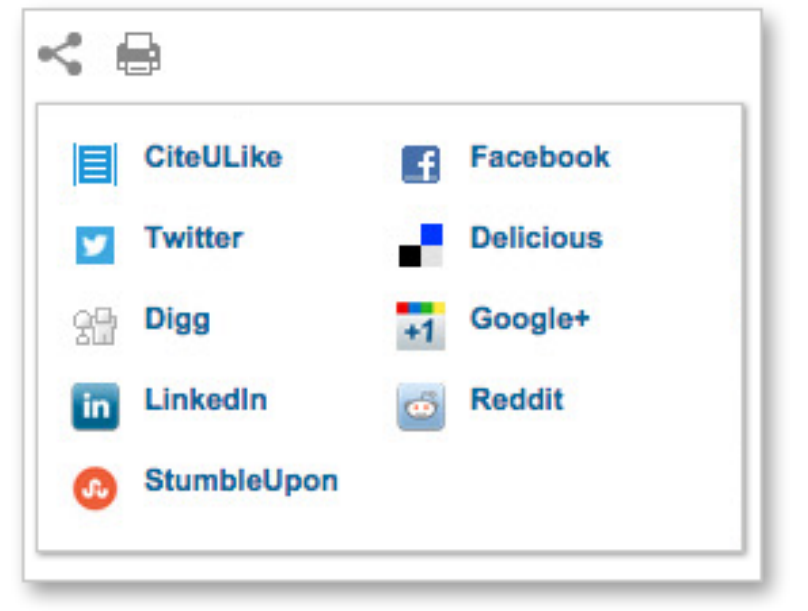

Fonte: Nature (2015).

Para comunicar a diferentes grupos de usuários, as revistas têm opção de organizar o conteúdo em áreas destinadas a públicos distintos. Esquemas abertos, orientados ao público, possibilitam que usuários de uma determinada audiência acessem o conteúdo de seu interesse. A Figura 7 mostra a página destinada a autores na revista Nature, onde conteúdos específicos de interesse dos autores são 
exibidos. Nas três revistas há espaços exclusivos como este, organizados por esquema ambíguo orientado ao público.

Figura 7 - Organização ambígua por público na revista Nature

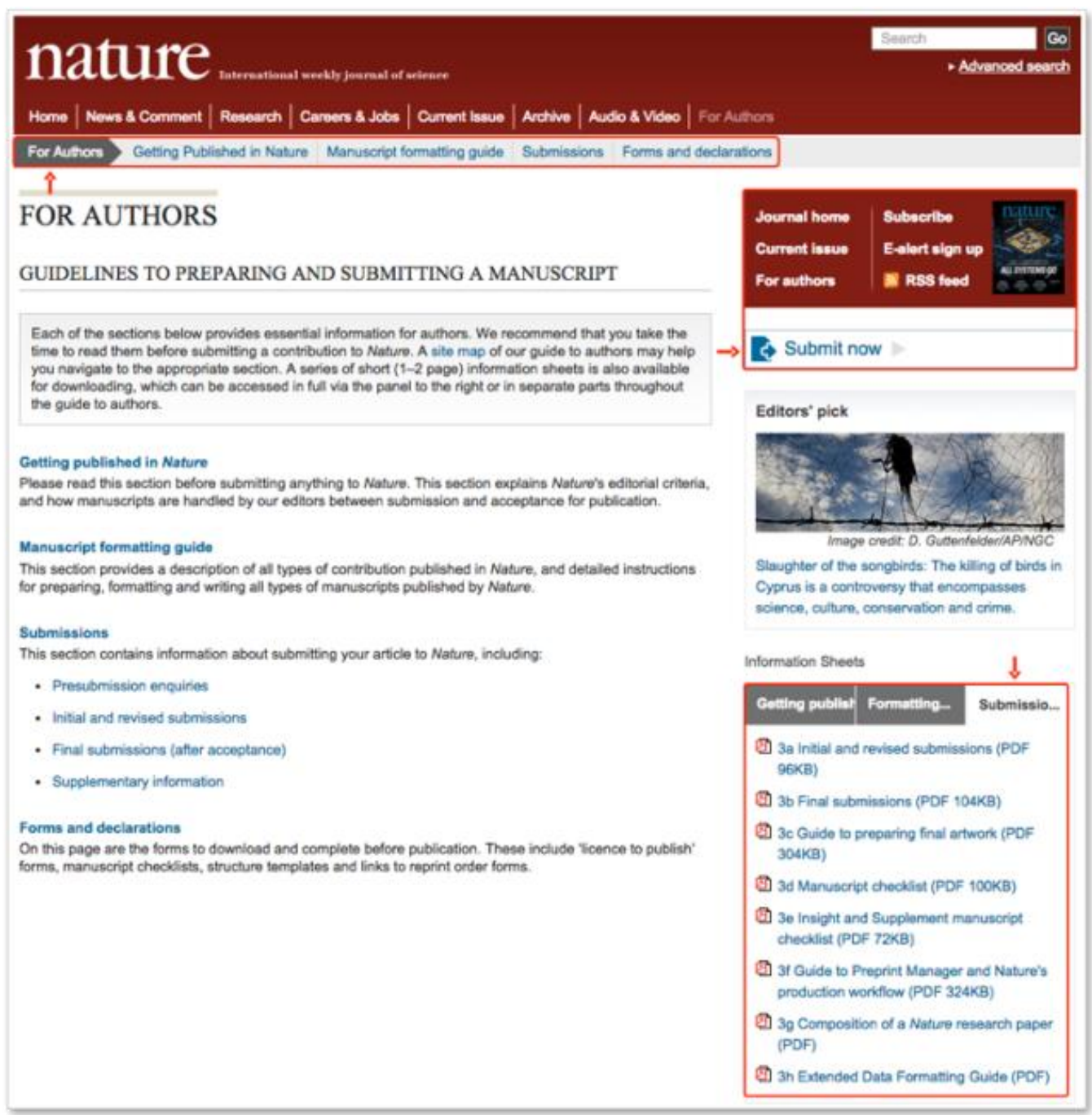

Fonte: Nature (2015).

Rosenfeld, Morville e Arango (2015) destacam que os esquemas orientados ao público podem também organizar o conteúdo do site em áreas restritas. Espaços dessa natureza evitam que os usuários visualizem, por engano, assuntos que não lhes interessam. Pode haver também áreas de acesso exclusivo para assinantes, como no exemplo da Figura 8 na revista Science. Para ter acesso ao artigo completo, é necessário ser um usuário cadastrado nesse nível. 
Figura 8 - Organização ambígua por público na revista Science

\begin{tabular}{|c|c|c|c|}
\hline \multicolumn{4}{|c|}{ Science } \\
\hline \multicolumn{4}{|c|}{$\begin{array}{l}\text { Cet instant online access to every Science article ever published. Plus, enjoy } 51 \text { weeks of home delivery of the } \\
\text { print or digital edition of Science and an one-year membership in the AAAS. }\end{array}$} \\
\hline \multicolumn{3}{|c|}{ Select your plan } & Help \\
\hline \multicolumn{3}{|c|}{ Science Digital and Online: $\quad$ Membership Category: } & \\
\hline \multicolumn{4}{|c|}{ Europe/Rest of World } \\
\hline 5155.00 & $\$ 50.00$ & Professional Member & \\
\hline 599.00 & $\$ 50.00$ & Postdoctoral/Resident & \\
\hline$\$ 75.00$ & $\$ 50.00$ & Student & \\
\hline \multicolumn{3}{|c|}{ Enter your information } & - required fields \\
\hline
\end{tabular}

Fonte: Science (2015).

A organização ambígua orientada à metáfora está presente nas três revistas analisadas. Devido ao carácter social e cultural das metáforas, sua aplicação é bastante delicada. Em alguns casos, o conceito alvo da metáfora pode não estar alinhado ao conceito de sua origem. Quando esse desalinhamento ocorre, o reconhecimento da metáfora é prejudicado. Por outro lado, quando as metáforas são bem conhecidas em uma dada cultura, país, ou região, a compreensão da mensagem se torna simples e direta. Assim, o uso de metáforas familiares no contexto de vida dos usuários pode contribuir para a organização da informação em uma interface. A Figura 9 mostra a conhecida metáfora das pastas de arquivo aplicada para organização ambígua na revista Science.

Figura 9 - Organização ambígua por metáfora na revista Science

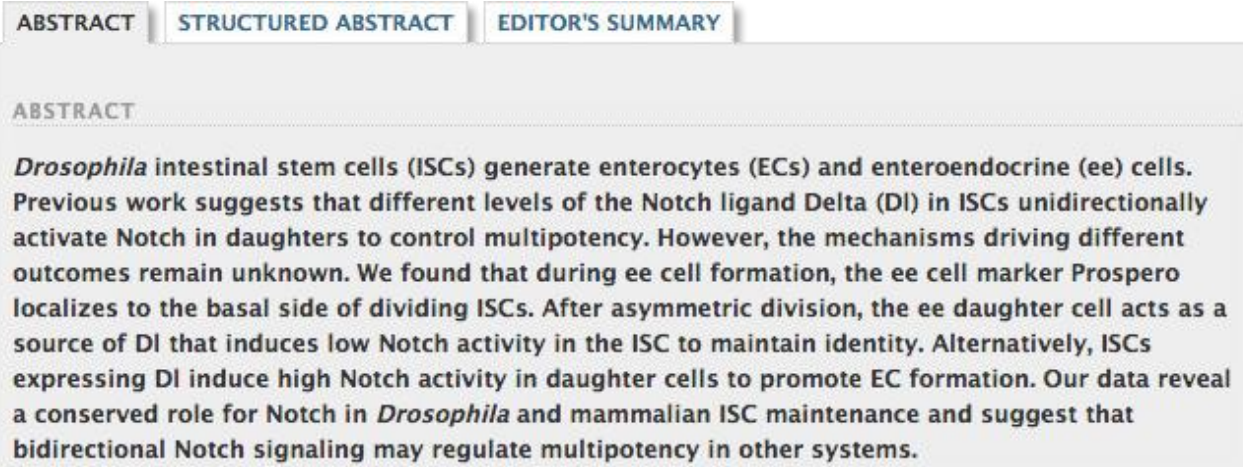

Fonte: Science (2015). 
No exemplo da Figura 10, também extraído da revista Science, a metáfora aplicada assemelha-se a uma mesa de luz, utilizada para seleção de imagens em estúdios fotográficos. Essa metáfora aparece muitas vezes em aparelhos móveis como tablets e smartphones.

Figura 10 - Organização ambígua por metáfora na revista Science

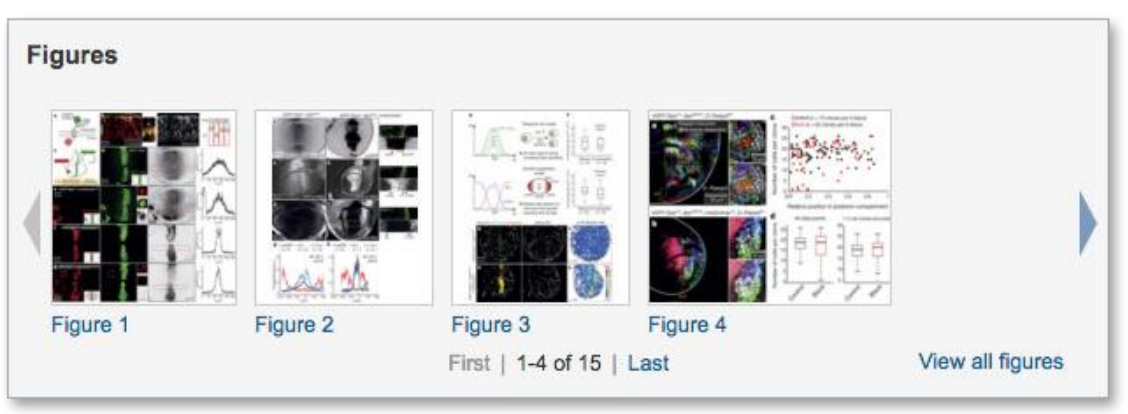

Fonte: Science (2015)

Segundo Kalbach (2009, p. 249), “As pessoas gostam de informações organizadas consistentemente. Mas as informações não se deixam categorizar de maneira clara, organizada e regular.". Muitas vezes, o conteúdo e a funcionalidade de um sistema impedem uma organização a partir de um único esquema. Para Rosenfeld, Morville e Arango (2015) as possibilidades de modos únicos de organização serem aplicados a grandes quantidades de conteúdo são relativamente pequenas. Na grande maioria dos casos, quando isso acontece, a integridade e a usabilidade do sistema são afetadas.

Os regimes híbridos ou mistos consistem na junção de esquemas exatos e ambíguos - em prol da organização e consistência da informação. Mas a solução não está em simplesmente combinar vários esquemas. Segundo Rosenfeld, Morville e Arango (2015, p. 115) o usuário não consegue formar um modelo mental quando a mistura de esquemas ocorre de maneira confusa, em várias camadas. Os autores afirmam que "[...] regimes híbridos rasos são bons, mas regimes híbridos profundos não são." Assim, os esquemas combinados devem estar presentes apenas em camadas superficiais de navegação. As Figuras 11, 12 e 13 fornecem exemplos de esquemas híbridos aplicados à navegação das revistas Nature, Science e PLOS Biology. 


\subsection{Estruturas}

Em relação às estruturas de organização empregadas nas revistas Nature, Science e PLOS Biology, a análise verificou se as estruturas hierárquicas, além de serem facilmente compreendidas, organizam o conteúdo em agrupamentos lógicos, partindo de assuntos gerais para assuntos específicos; se as estruturas de dados relacionados possibilitam a fácil pesquisa, navegação, filtragem e vinculação da informação, partindo de assuntos específicos para os gerais; e se as estruturas de hipertexto possibilitam uma navegação orgânica a partir de componentes interligados por links.

A análise permitiu observar que as revistas Nature, Science e PLOS Biology organizam as informações hierarquicamente em agrupamentos lógicos, partindo de assuntos gerais para assuntos específicos. Isso fica claro observando seus menus de navegação principal (Figuras 11, 12 e 13). A organização hierárquica é amplamente aplicada na internet por ser de fácil compreensão para o usuário (GARRETT, 2011). Segundo Rosenfeld, Morville e Arango (2015), o sistema hierárquico auxilia o usuário a rapidamente criar um modelo mental do ambiente e de sua localização dentro desta estrutura.

Um dos princípios universais do design é a hierarquia. De acordo com Lidwell, Holden e Butler (2010), a hierarquia torna mais simples a compreensão de temas complexos, aumentando a visibilidade das relações entre os elementos de um sistema. Rosenfeld, Morville e Arango (2015) lembram que o ser humano organiza a informação por meio de hierarquias desde os primórdios da história. Eles afirmam que a divisão da vida na terra (reinos, classes, espécies) e a árvore genealógica representam maneiras humanas básicas de organização em hierarquia.

Identificou-se também, nas revistas analisadas, a presença de base de dados relacional. Rosenfeld, Morville e Arango (2015) afirmam que a maioria dos grandes bancos de dados disponíveis na internet utiliza esse modelo. Nas três revistas analisadas, essa estrutura é aparente devido à presença na interface de mecanismos de filtragem avançada e classificação de resultados de busca. Mecanismos para geração automática de índices também estão presentes nas revistas Science e PLOS Biology. Esta última ainda conta com apresentação 
dinâmica e associativa de links. Esses mecanismos indicam a estruturação por base de dados relacional.

De acordo com Rosenfeld, Morville e Arango (2015), as estruturas de base de dados relacionais tornam possível, através de metadados e vocabulário controlado, aplicar os benefícios de bancos de dados em ambientes não estruturados. Conforme os autores, as estruturas de banco de dados, marcações com metadados e os vocabulários controlados possibilitam a fácil pesquisa, navegação, filtragem e vinculação dinâmica. Essas características são úteis para a busca em sites de revistas científicas.

O uso de hipertexto é evidente em toda a estrutura das três revistas (Figuras 11, 12 e 13). Para Rosenfeld, Morville e Arango (2015), apesar de fornecerem uma grande versatilidade, as estruturas de informação com base em hipertexto apresentam alto potencial para gerar equívocos. Isso se deve ao fato de que as ligações feitas para conectar texto, dados, imagens, vídeos, áudios e pedaços de hipertexto são conexões sobremodo pessoais. As ligações de conteúdo feitas nesta estrutura de organização não são claras para todos os usuários. É possível que a relação suave, desenhada para um usuário, implique em grandes saltos de navegação para outros usuários.

Por consequência, esta estrutura de organização não é indicada como estrutura de organização principal. Em contrapartida, quando combinada com outras estruturas, pode permitir relações uteis e criativas. Rosenfeld, Morville e Arango (2015) afirmam que cada uma delas apresenta aspectos positivos e negativos, e que, por vezes, faz sentido optar por uma ou outra. Mas há casos em que o mais indicado é utilizá-las de maneira integrada.

As revistas Nature, Science e PLOS Biology integram os três tipos de estruturas de organização, como mostram as Figuras 11, 12 e 13, onde também há destaque para os esquemas de organização e para a classificação social, vista no próximo tópico. 
Figura 11 - Sistema de organização na revista Nature

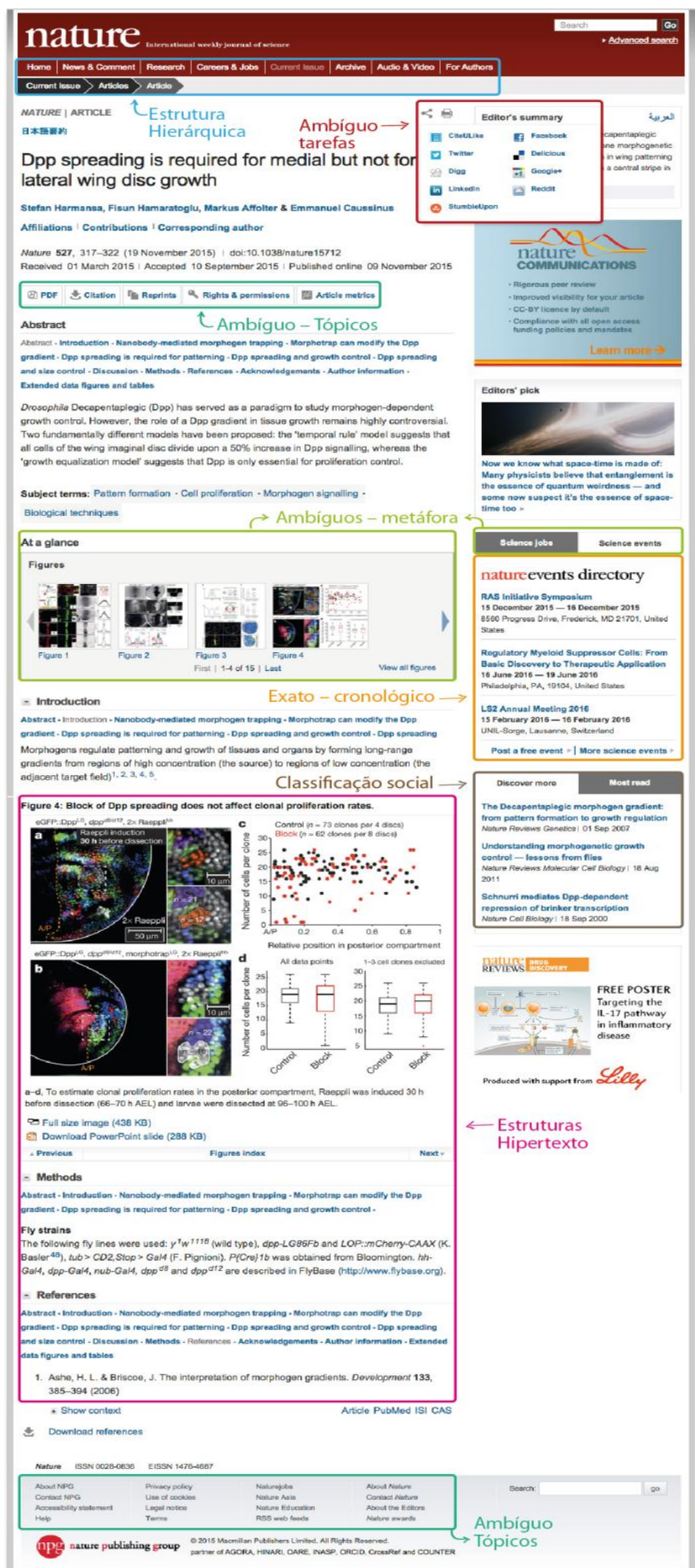

Fonte: Adaptado pelas autoras a partir de Nature (2015). 
Figura 12 - Sistemas de organização na revista Science

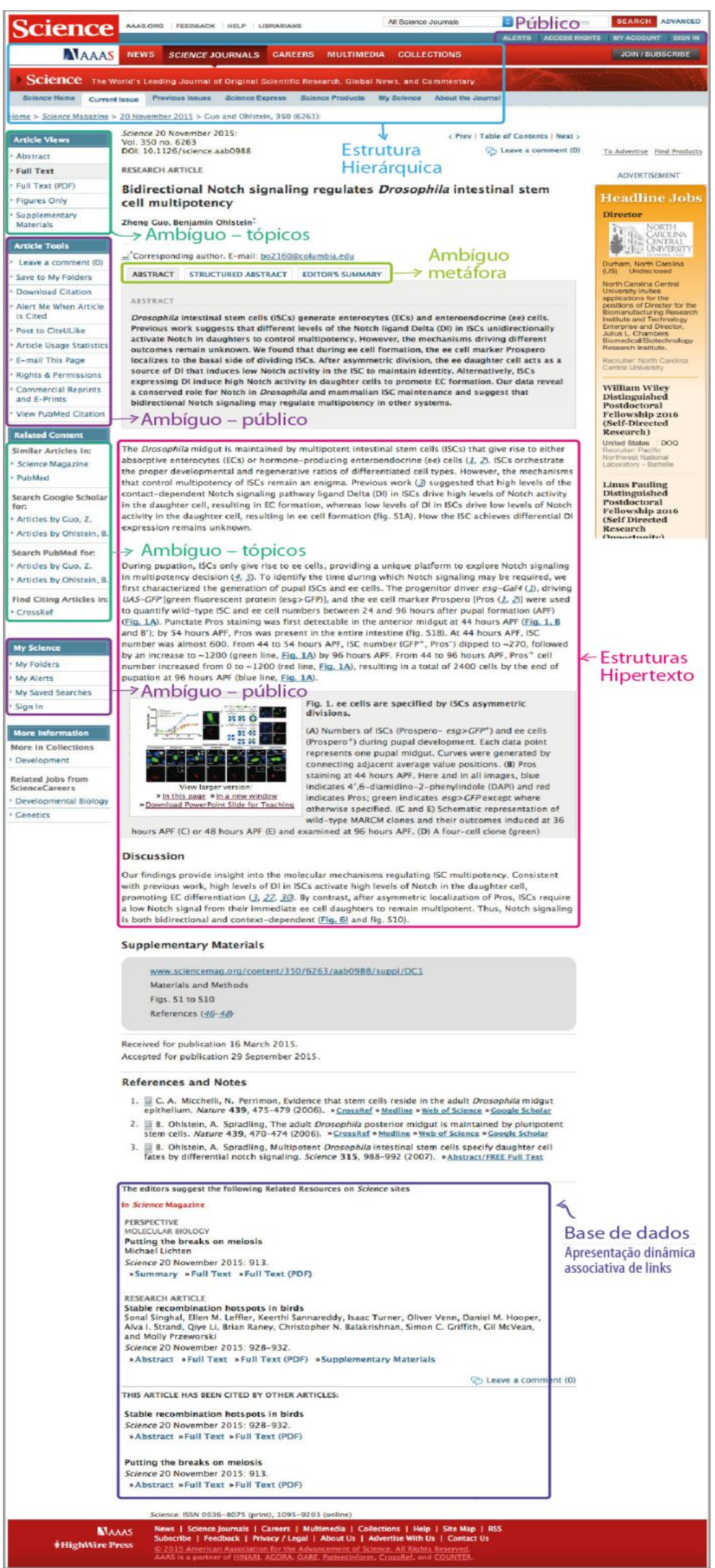

Fonte: Adaptado pelas autoras a partir de Science (2015). 
Figura 13 - Sistemas de organização na revista PLOS Biology

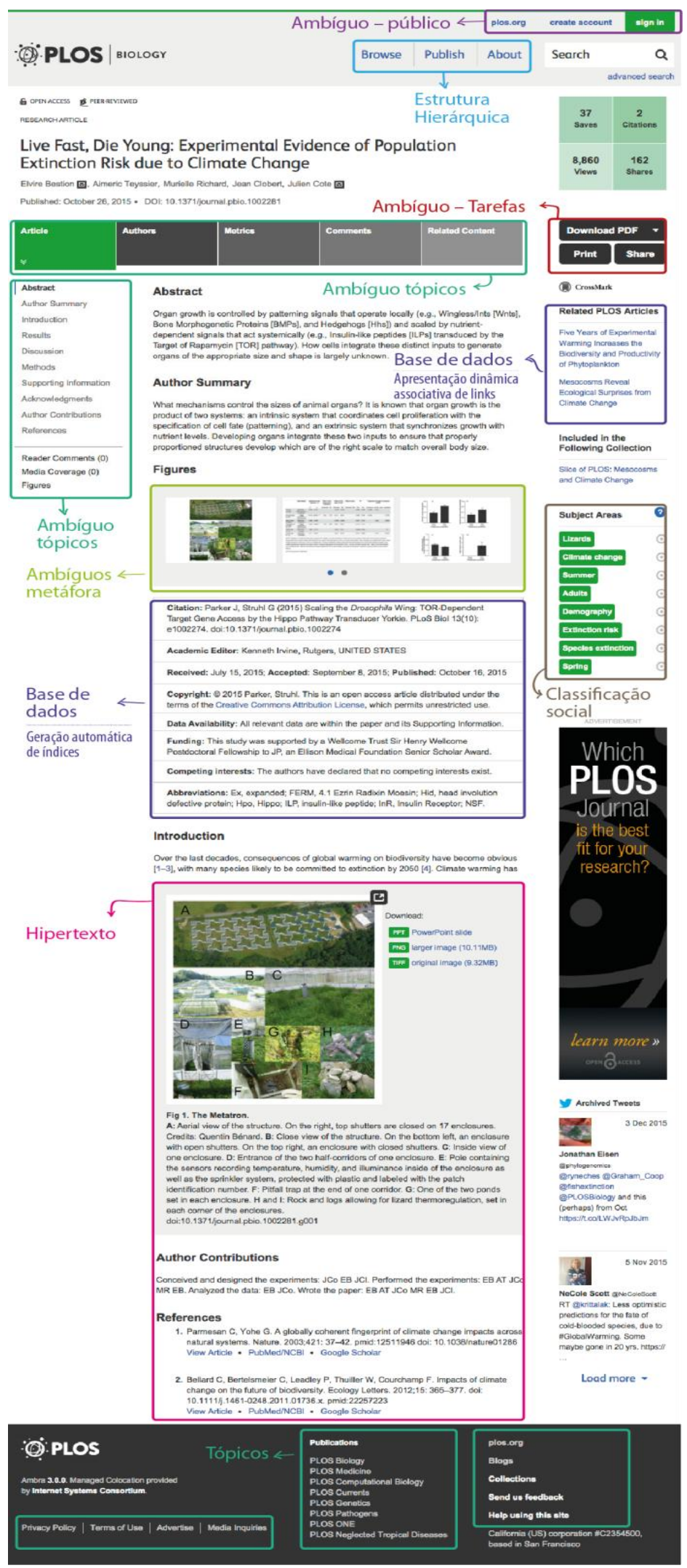

Fonte: Adaptado pelas autoras a partir de PLOS Biology (2015). 


\subsection{Classificação colaborativa}

Quanto à organização por classificação colaborativa, a pesquisa verificou se o sistema oferece, diferentemente dos vocabulários controlados (rígidos e impessoais), maneiras alternativas de classificar informações digitais baseadas na organização colaborativa do conteúdo e gerada a partir de marcações (tags) feitas pelos usuários.

Observou-se que as revistas PLOS Biology e Nature permitem a classificação social por meio de encaminhamento para as principais redes de compartilhamento de conteúdo, como Twitter, Facebook, Google Plus, entre outras. A revista Science não apresentou opções de marcação. A Figura 14 mostra a página de comentários da revista PLOS Biology, com a informação de possibilidade de marcação de tags em destaque.

Figura 14 - Classificação social na revista PLOS Biology

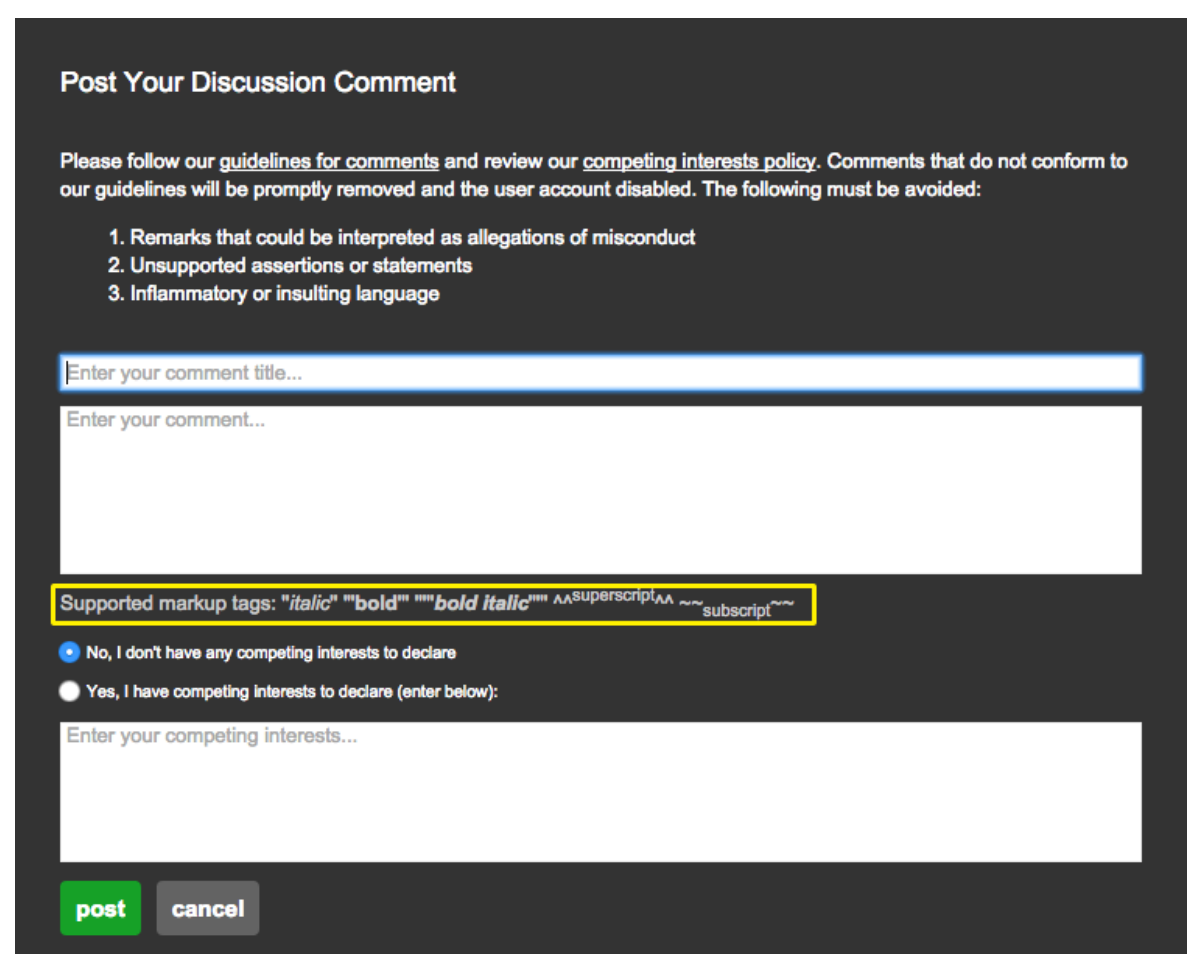

Fonte: PLOS Biology (2015).

Na revista PLOS Biology, é possível, também, realizar uma marcação controlada, com a finalidade de identificar as áreas relacionadas a um artigo 
específico, como mostra a Figura 13. A classificação colaborativa feita pelos usuários das revistas em ambientes externos é monitorada e compõe as métricas dos artigos.

De acordo com Rosenfeld, Morville e Arango (2015), a classificação gerada pela etiquetagem do usuário coloca-se como uma respeitável ferramenta de organização de informações. Atualmente, centenas de milhões de pessoas compartilham fotos, vídeos, expressam seus interesses e interagem com outros usuários instantaneamente por meio de plataformas como Facebook e Twitter. Por conta disso, a experiência digital impactada pela mídia social ganha novas dimensões.

\section{Considerações finais}

Em relação ao sistema de organização, é importante destacar a classificação social. A participação das pessoas na rede colocou em evidência a organização colaborativa da informação. Por meio de marcações dos usuários com as populares hashtags, é realizada uma organização do conteúdo disponível na internet em nível global. Essa prática se tornou comum e ajuda na identificação dos assuntos mais tratados nas redes sociais.

A classificação social poderia contribuir para maior divulgação, bem como para melhor recuperação dos textos científicos. No entanto, as opções para marcação nas revistas, como foi visto nas análises, ainda não exploram todo o potencial desse recurso. As revistas PLOS Biology e Nature permitiram a classificação social apenas por meio de encaminhamento para as principais redes sociais. Já a revista Science não apresentou opções de marcação. Seria interessante que existissem recursos para marcação dos textos nas próprias revistas, assim como é possível marcar os comentários na revista PLOS Biology.

A verificação sistemática e aprofundada das revistas Nature, Science e PLOS Biology, permitiu conhecer os sistemas de organização desses veículos de ponta e indicar possibilidades de melhorias, como demonstra a seção de resultados deste artigo. À luz da literatura da área, foi possível identificar 
pontos onde algumas modificações trariam benefícios à experiência dos usuários das revistas. Além disso, por meio da comparação entre as três revistas, foi possível ressaltar as melhores soluções aplicadas para cada um dos mecanismos de organização.

O mapeamento dos esquemas e das estruturas de organização nas revistas de alta visibilidade pretende servir como fundamentação para o aprimoramento de outras revistas científicas. Considerando que as revistas científicas se constituem atualmente nos principais veículos de comunicação científica, entende-se que devem ser realizadas constantes avaliações com o intuito de promover a qualificação dos sistemas e a visibilidade dos textos publicados.

\section{Financiamento}

Esta pesquisa é vinculada ao pós-doutorado realizado na Universidade Federal do Rio Grande do Sul, com bolsa financiada pela Coordenação de Aperfeiçoamento de Pessoal de Nível Superior (CAPES).

\section{Referências}

BRAGA, G. M.; OBERHOFER, A. Diretrizes para avaliação de periódicos científicos e técnicos brasileiros. Revista Latinoamericana de Documentación, Brasília, v. 2, n. 1, p. 27-31, 1982.

CHRESSANTHIS, G. A., CHRESSANTHIS, J. D. The relationship between manuscript submission fees and journal quality. Serials Librarian, New York, v. 24, n. 1, p. 71-86, 1993.

FACHIN, G. R. B. Modelo de avaliação para periódicos científicos on-line: proposta de indicadores bibliográficos e telemáticos 2002. Dissertação (Mestrado em Engenharia de Produção) - Programa de Pós-Graduação em Engenharia de Produção, Universidade Federal de Santa Catarina, Florianópolis, 2002.

FRANCKE, H. (Re)creations of scholarly journals document and information architecture in open access journals distribution. 2008. Thesis ( $\mathrm{PhD}$ in Library and Information Science) - Swedish School of Library and Information Science, University College of Borås, Borås, 2008. 
FRANCKE, H. Towards an architectural document analysis. Journal of Information Architecture, Copenhagen, v. 1, n. 1, p. 16-36, 2009.

GARRETT, J. J. The elements of user experience: user centered design for the Web and beyond. 2nd ed. Berkeley: New Riders, 2011.

KALBACH, J. Design de navegação web. Porto Alegre: Bookman, 2009.

KRZYZANOWSKI, R. F.; KRIEGER, E. M.; DUARTE, F. A. M. Programa de apoio às revistas científicas para a Fapesp. Ciência da Informação, Brasília, v. 20, n. 2, p. 137-150, jul./dez. 1991.

LIDWELL. W; HOLDEN, K; BUTLER, J. Princípios universais do design, Porto Alegre, Bookman, 2010.

MUKHERJEE, B. Scholarly communication in library and information services: the impacts of Open Access journals and e-journals on a changing scenario. Oxford: Elsevier Science; Chandos Publishing, 2010.

NATURE. London: Springer Nature, 2015. Disponível em: <http://www.nature.com>. Acesso em: 5 dez. 2015.

PASSOS, P. C. S. J. et al. Critérios de qualidade em periódicos científicos: um estudo a respeito da adequação ao meio digital. Informação e Sociedade, João Pessoa, 2018. No prelo.

PLOS BIOLOGY. San Francisco: PLOS, 2003. Disponível em: <http://journals.plos.org/plosbiology>. Acesso em: 5 Jan. 2015.

PREECE, J.; ROGERS, Y.; SHARP, H. Interaction Design: beyond humancomputer interaction. Glasgow: Bell \& Bain, 2015.

ROSENFELD, L.; MORVILLE, P.; ARANGO, J. Information Architecture: for the web and beyond. Sebastopol: O'Reilly, 2015.

RUSSELL-ROSE, T.; TATE, T. Designing the search experience: the Information Architecture of discovery. Burlington: Morgan Kaufmann, 2013.

SARMENTO E SOUZA, M. F. Periódicos científicos eletrônicos: apresentação de modelo para análise de estrutura. 2002. Dissertação (Mestrado em Ciência da Informação) - Faculdade de Filosofia e Ciências, Universidade Estadual Paulista, Marília. 2002.

SCIENCE. Washington: AAAS, 2015. Disponível em: <http://www.sciencemag.org>. Acesso em: 5 Dec. 2015.

WODTKE, C.; GOVELLA, A. Information Architecture: blueprints for the Web. 2nd. ed. Berkeley: New Riders, 2009. 
ZUDILOVA-SEINSTRA, E. et al. The Elsevier Article of the Future project: a novel experience of online Reading. In: COPE, B.; PHILLIPS, A. (Ed.). The

Future of the academic journal. 2nd ed. Oxford. Chandos Publishing, 2014. p. 357-377.

\title{
The content organization in scientific journals: an analysis of Information Architecture
}

\begin{abstract}
Organization is a component of Information Architecture that deals with system content classification. In electronic journals, organization impacts user interaction with the content and the visibility of published articles. Thus, the objective of this article is to verify how the organization systems of electronic scientific journals work. For the analysis, three journals of relevance to science and with high impact factors in the multidisciplinary area were selected: Nature, Science and PLOS Biology. The method chosen was the inspection by checklist, which was performed through the test sentences, described with basis on reference authors in the area. The analysis considered if organizational schemas divide information into defined and unique sections when used in journals, and if they support an associative learning process that enables the user to make new connections. It was also verified if the structures used in journals organize the content into logical groupings and benefit the research, navigation, filtering and linking of the information. In addition to the traditional schema and organizational structures, the study also verifies if journals present alternative ways of classifying digital information based on the collaborative content organization generated from user tags. As results, the research presents the mapping of the organization systems of the journals that were analyzed. These results can be applied to improve other scientific journals and their systems.
\end{abstract}

Keywords: Scientific journal. Information architecture. Organization system.

Recebido: 24/01/2018

Aceito: 01/06/2018 